\title{
DO ETHOS SÓBRIO AO DIVERTIDO EM ENUNCIAÇÕES SOBRE A MORTE: UMA ANÁLISE DE PÁGINAS INSTITUCIONAIS NO FACEBOOK
}

\author{
CRISTINA ROTHIER DUARTE ${ }^{1}$, FRANCISCO VIEIRA DA SILVA ${ }^{2}$
}

Programa de Pós-Graduação em Letras, Universidade Federal da Paraíba Cidade Universitária, s/n - Castelo Branco III - 58051-085 - João Pessoa - PB - Brasil

Programa de Pós-Graduação em Letras, Universidade Estadual do Rio Grande do Norte BR 405, Km 153 - Bairro Arizona - 59900-000 - Pau dos Ferros - RN - Brasil

cristinarothier@hotmail.com, francisco.vieiras@ufersa.edu.br

\begin{abstract}
Resumo. Este artigo tem como objetivo analisar o ethos de duas páginas institucionais criadas no Facebook, no intuito de investigar como criam uma imagem de si a partir de enunciações publicadas em suas timelines. Para a realização deste estudo, tomamos como aporte teórico os estudos da Análise do Discurso de linha francesa, especialmente, os conceitos de ethos e de cena de enunciação trabalhados por Maingueneau, bem como o exame sobre o Facebook empreendido por Emediato. Como resultado, verificamos, com base na análise do corpus, que os enunciadores podem apresentar cenografias e ethé distintos, mediante a utilização de elementos discursivos de acordo com a sua intenção, provocando, assim, reações diferentes de seus coenunciadores. Palavras-chave: ethos; Análise do Discurso; Facebook.
\end{abstract}

\begin{abstract}
This article has as objective to analyse the ethos of two institutional pages created on Facebook, in the intention of investigating how they create an image of themselves from enunciations published in their timelines. For the realization of this study, we take as theoretical support the studies of the Discourse Analysis of French line, specially, the concepts of ethos and enunciation scene worked by Maingueneau, as well as the Facebook exam undertaken by Emediato. As result, we check, on basis of the analysis of the corpus, that the enunciating can present different set designs and ethé, by means of the use of discursive elements in accordance with its intention, provoking, so, different reactions from its co-enunciating.
\end{abstract}

Keywords: ethos; Discourse Analysis; Facebook.

\footnotetext{
${ }^{1}$ Mestranda em Letras pela Universidade Federal da Paraíba.

${ }^{2}$ Doutorado em Linguística pela Universidade Federal da Paraíba. Docente de Linguística e Língua Portuguesa na Universidade Federal Rural do Semi-Árido (UFERSA), Campus de Caraúbas e Professor Permanente do Programa de Pós-Graduação em Letras da Universidade do Estado do Rio Grande do Norte.
} 


\section{Introdução}

O compartilhamento de experiências pessoais, informações, ideias e opiniões tem sido um dos principais motivos que ancoram o engajamento de pessoas nas redes sociais. No entanto, para além desse papel, esses ambientes da web, destacadamente o Facebook, inserem-se na sociedade contemporânea como uma importante ferramenta interacional, revelando-se como uma fonte fértil para diversos estudos da linguagem, devido ao seu propósito comunicacional.

Não obstante a importância que o Facebook vem assumindo no nosso cotidiano, as pessoas, de uma forma geral, ainda o enxergam apenas como um espaço para os citados compartilhamentos, em que, por meio de publicações, contam um pouco da sua vida particular, expõem suas alegrias e dissabores, bem como vivenciam histórias alheias, sem, contudo, observarem que os discursos envolvidos nesse ambiente podem contribuir fortemente para o seu engajamento nessa rede social, bem como podem levá-las à aquisição de hábitos de consumo, à assunção de posicionamentos ideológicos, entre outros comportamentos adquiridos por influência desse espaço virtual.

$\mathrm{Na}$ área das ciências da linguagem, de um modo geral, tem-se evidenciado o interesse sobre a forma como o enunciador constrói o seu ethos segundo uma abordagem teórica (MUSSALIM, 2008), bem como segundo uma abordagem analítica, ora tratando do ethos na política (BARROS, 2010), ora nos discursos de autoajuda (CERCATO, 2007), inclusive, o ethos tem sido estudado em discursos que circulam nas redes sociais (CARREIRA, 2012; DOMINGUES, 2014), no entanto, os estudos científicos que investigam o ethos ainda não se debruçaram sobre a perspectiva a que nos dedicaremos, havendo poucas pesquisas sobre o ethos institucional em redes sociais. Diante dessa conjuntura, entendemos que esta investigação se mostra relevante, pois promove, a partir da proposta teórica da Análise do Discurso, o estudo de páginas do Facebook, apresentando um olhar crítico sobre a maneira como os perfis se mostram no âmbito dessa rede.

Assim, partindo da apresentação do aporte teórico sobre o Facebook (EMEDIATO, 2015) e sobre o ethos e seus planos: ethos pré-discursivo, ethos dito e ethos propriamente discursivo ou mostrado (MAINGUENEAU, 2004, 2008, 2010, 2016), investigamos como se constrói o ethos do sujeito enunciador em páginas de natureza institucional no Facebook, tendo como objetivo investigar os elementos discursivos que instauram a emergência do ethos em páginas institucionais.

A metodologia empregada é a pesquisa descritivo-interpretativa de cunho qualitativo, da qual nos utilizamos para a realização da revisão da base teórica em Análise do Discurso de linha francesa, para o estudo das páginas institucionais do Facebook: Cemitério Jardim da Ressurreição e Parque das Acácias, selecionadas como corpus da presente pesquisa, a partir das quais verificamos como as suas imagens são construídas, levando-se em consideração o ethos discursivo. 


\section{Seção teórico-metodológica}

\subsection{A construção do ethos do enunciador sob a ótica da Análise do Discurso}

Ao termos acesso a um texto, conferimos um tratamento específico a ele, dependendo do tipo de discurso que o atravessa, o gênero que se enquadra e o suporte em que circula. Por exemplo: lemos uma receita médica de forma completamente diferenciada da leitura de um romance; lemos uma notícia que circula em uma revista informativa de maneira diversa da que é publicada, por meio de link, na linha do tempo do Facebook de um amigo; lemos uma oração também de forma diferente da que lemos uma proposta política, um contrato ou uma propaganda, bem como recebemos de formas distintas o conselho de nossa mãe e o de um desconhecido. Para cada situação descrita, em regra, criamos expectativas e conferimos tratamentos distintos ao texto.

Diante disso, é preciso compreendermos que essa forma como tratamos as enunciações mantém estrita relação com o conceito de cena de enunciação e o de ethos do enunciador.

Voltando a alguns dos nossos exemplos, podemos aferir que, no caso da receita médica, somos inseridos em uma cena em que o enunciador é um médico - profissional habilitado para tratar da saúde - e o coenunciador é interpelado como paciente - indivíduo que deve se submeter às instruções do enunciador para, via de regra, manter ou recuperar sua saúde. Já no caso do romance, somos inseridos uma cena de enunciação em que figuram autor e leitor como enunciador e coenunciador respectivamente, e, sendo o conteúdo da enunciação ficcional, assim é ele recebido pelo coenunciador. Além da cena de enunciação, outro aspecto que irá influenciar o tratamento que conferimos à enunciação será o ethos - a imagem que temos do enunciador -, podendo a enunciação (receita ou romance) influenciar, positivamente ou não, na construção dessa imagem.

A respeito da cena de enunciação, Maingueneau (2004) apresenta uma tripla interpelação, qual seja: a cena englobante, a cena genérica e a cenografia. A cena englobante refere-se a um tipo de discurso: religioso, político, publicitário etc. Nessa cena, segundo o autor, situamo-nos para interpretar a enunciação. A cena genérica referese ao gênero do discurso cuja função é desempenhar determinado papel social a que se destina. A cenografia é, por sua vez,

[...] um processo de enlaçamento paradoxal. [...] é ao mesmo tempo a fonte do discurso e aquilo que ele engendra; ela legitima um enunciado que, por sua vez, deve legitimá-la, estabelecendo que essa cenografia onde nasce a fala é precisamente a cenografia exigida para enunciar como convém, segundo o caso, a política, a filosofia, a ciência, ou para promover certa mercadoria. (MAINGUENEAU, 2004, 87-88, grifos no original)

A fim de exemplificar o conceito de cenografia, Maingueneau traz o seguinte exemplo de uma propaganda de produto de emagrecer:

Que reunião! Esses cafés da manhã de negócios, todos aqueles croissants, aqueles pãezinhos, era tanta tentação que não pude resistir... Mas eu vou dar um jeito nisso. Ao meio-dia, vou reagir. Um encontro 
com a boa forma: somente WEEK-END e eu. Prático, esses saquinhos que a gente carrega onde vai. Sabor de baunilha ou de legumes, meus quilinhos a mais logo vão sumir. Os intervalos para a boa forma WEEKEND e seus cardápios equilibrados, isso conta muito na agenda de uma gulosa. (2004, p. 85)

Nessa propaganda, poderia aparecer um sujeito enunciador destinando a enunciação diretamente para o público consumidor, mostrando os pontos positivos do produto, assim, promovendo-o; no entanto, o enunciador cria uma cenografia específica em que há uma mulher de negócios que fala de sua vida agitada e das vantagens do produto, objeto da propaganda, para mantê-la na dieta de forma saudável.

Além da cena de enunciação, de acordo com o exposto, o ethos, a imagem do enunciador construída pelo coenunciador por meio de pistas enunciativas e outros elementos, também influencia este a receber a enunciação de uma forma ou de outra, uma vez que, a partir dele, a personalidade do enunciador é revelada (MAINGUENEAU, 2004).

A concepção de ethos apresenta não apenas uma dimensão verbal, a do discurso, mas também, de acordo com Maingueneau (2008), um conjunto de determinações físicas e psíquicas ligadas ao fiador por meio de representações estereotipadas adotadas pela coletividade, o que significa dizer que ao ethos são atribuídos: uma corporalidade (dimensão física) e um caráter (dimensão psíquica). E vai “[m]ais além, o ethos implica uma maneira de se mover no espaço social, uma disciplina tácita do corpo apreendida através de um comportamento" (MAINGUENEAU, 2008, p. 18).

Afora as dimensões física e psíquica, Maingueneau (2008) estabelece como planos do ethos: o ethos pré-discursivo, o ethos discursivo ou mostrado e o ethos dito. $\mathrm{O}$ ethos pré-discursivo trata-se de um ethos não discursivo, uma vez que o destinatário o constrói a partir de informações que ele já possui acerca do enunciador, antes de ter acesso à enunciação que poderá confirmar ou não o ethos pré-discursivo. $\mathrm{O}$ ethos dito, por sua vez, constitui informações fornecidas pelo enunciador sobre si que contribuirão para a construção do ethos não-discursivo que, por seu turno, será confrontado pelo destinatário com o ethos discursivo. Por fim, o ethos discursivo ou mostrado é construído a partir indícios textuais presentes na enunciação:

[...] escolhas de ordem lexical, complexidade da sintaxe, ritmo das frases, jogos de planos enunciativos (parênteses, ironia, paródias...) etc., mas também qualidade ortográfica ou riqueza e natureza cultural (uma alusão a tal pintor italiano da Renascença, a tal escritor contemporâneo, ao rock ou ao rap...). (MAINGUENEAU, 2010, p. 84)

Em seus estudos sobre o ethos em sites de relacionamento, Maingueneau (2010) ainda cita dois outros planos do ethos: o pseudônimo e o ethos construído a partir de fotos do dono da página do site de relacionamento. Segundo o autor, "o pseudônimo contribui fortemente para a construção de um ethos discursivo. Ele influi tanto na produção quanto na leitura: esperamos do anunciante que enuncie em função do pseudônimo escolhido" (MAINGUENEAU, 2010, p. 83). Quanto ao ethos construído a partir das fotos, ele entende que "convergentes ou não com o ethos discursivo, essas fotos inevitavelmente levam o destinatário a construir um ethos" (MAINGUENEAU, 2010, p. 84). 
Devemos notar, todavia, que, como nosso estudo está direcionado para enunciações de instituições que possuem páginas no Facebook, o pseudônimo não nos interessa. Quando ao ethos construído a partir das fotos da página do Facebook, acreditamos que ele se constitui como um plano de relevância para a análise que procederemos.

Além desses elementos importantes para a análise do discurso, não podemos negligenciar o papel do mídium. Maingueneau, a respeito, entende que

[...] o mídium não é um simples meio de transmissão do discurso, mas que ele imprime um certo aspecto a seus conteúdos e comanda os usos que dele podemos fazer. O mídium não é um simples meio, um instrumento para transportar uma mensagem estável: uma mudança importante do mídium modifica o conjunto de um gênero de discurso. (MAINGUENEAU, 2004, 71-71, grifos no original)

Em outras palavras, o mídium é o portador do texto, é o locus físico ou virtual que serve de base de fixação do gênero materializado como texto (MELO, 2013), conferindo determinada feição ao enunciado. No caso do nosso estudo, o Facebook configura esse mídium, ou seja, local onde as enunciações são publicadas, e outorga determinado aspecto às enunciações que nele circulam.

\subsection{O Facebook como espaço discursivo}

Levando em consideração o papel que o Facebook desempenha em relação às enunciações que divulga, é necessário, para a presente pesquisa, conhecermos seu conceito no campo da Análise do Discurso, algumas de suas funcionalidades relacionadas às enunciações, como as ações de publicar, curtir, comentar e compartilhar, bem como as atitudes enunciativas e os comportamentos adotados pelos enunciadores nesse ambiente virtual.

Reis (2015, p.39) explica que "sites de redes sociais propriamente ditos são aqueles que compreendem a categoria dos sistemas focados em expor e publicar as redes dos usuários. Seu foco principal está na exposição pública das redes conectadas aos usuários". Tratando especificamente do Facebook, a pesquisadora entende que a interação nessa rede social tem como ponto de partida a criação de um perfil do usuário. Criado o perfil, é possível convidar outros usuários - donos de perfis - com os quais aquele irá interagir mediante diversas formas de trocas interacionais. Para a autora,

[a] criação de um perfil em uma rede social como o Facebook, por exemplo, permite ao usuário não somente a exposição de sua vida pessoal como também de seus gostos pessoais, seus valores morais e sociais, ou seja, suas ideologias. O Facebook é uma rede social que permite a interação não só entre usuários, mas também entre textos, gêneros, discursos e enunciados. (REIS, 2015, p. 39)

Como podemos perceber, a autora constrói uma conceituação predominantemente descritiva e funcional do Facebook. Por outro lado, Emediato (2015) desenvolve o seu conceito de Facebook de forma intimamente relacionada ao aspecto discursivo que 
compreende esse ambiente. Para o autor, o Facebook é uma rede de discursos, um espaço retórico por natureza, onde podemos encontrar tudo que se pode supor no universo de discursos e nos espaços discursivos. Em seus estudos, Emediato (2015) enumera como características do Facebook:

a) a ocorrência de interação entre códigos semiológicos, em especial, a verbovisualidade, o que significa dizer que os enunciados geralmente apresentam um suporte visual (imagem etc.). "Raramente um post no facebook vem sem um suporte visual, que pode ser produzido pelo próprio sujeito ou pela capacitação de imagens na própria rede ou outros suportes, o que implica um trabalho importante de busca ou por via do compartilhamento" (EMEDIATO, 2015, p. 173);

b) a existência de modalidades de interação que permitem o dialogismo interlocutivo e a aproximação das formas dialogais, proporcionando a copresença espacial (publicação, ação de curtir, de comentar e de compartilhar); e

c) organização interacional ou conversacional, cujos interlocutores são o locutor, o alocutário e um terceiro destinatário indireto de natureza coletiva cuja interação se dá pelas modalidades citadas no item $b$.

Ações de publicar, de curtir, de comentar e de compartilhar são, segundo Emediato (2015), atos de linguagem utilizados pelos sujeitos que participam do dialogismo interacional no Facebook.

A publicação é uma enunciação em que o locutor pode se manifestar de diversas formas, compartilhando com seus amigos ou com o público em geral - dependendo da configuração da sua conta - um pensamento, um sentimento, uma citação, um acontecimento que está experimentando, uma imagem, um local em que está (check-in) etc.

O curtir é um ato kinésico, ou gestual, e, em regra, representa "uma apreciação implícita de cunho eletrônico, ou seja, trata-se de um sinal eletrônico que significa, em geral, um ato apreciativo positivo, mas não-verbal” (EMEDIATO, 2015, p. 174).

O comentário é uma publicação de caráter verbal em que o locutor pode expressar "uma apreciação positiva, negativa ou um julgamento axiológico, uma concordância ou uma discordância, conforme o caso" (EMEDIATO, 2015, p. 174), por isso considerado mais complexo que o curtir.

$\mathrm{O}$ ato de linguagem compartilhar, por fim, trata-se de uma "adesão mais intensa, já que, além de expressar concordância com a publicação, o interlocutor se associa, ou seja, adere à publicação e tem interesse particular em amplificar a sua divulgação" (EMEDIATO, 2015, p. 175). Ocorre que, nem sempre, o compartilhar apresentará a intenção de concordância, tendo em vista que o locutor poderá compartilhar uma publicação com a qual não concorda, fazendo-o tão somente para contextualizar a crítica que pretende apresentar.

Quanto às atitudes enunciativas, de acordo com Emediato (2015), o Facebook apresenta três espécies que podem ser praticadas pelo locutor:

a) atitudes enunciativas egocentradas - aquelas voltadas para a exibição de si. 
b) atitudes enunciativas alocentradas - aquelas em que o locutor se voltada para o tu coletivo e indeterminado;

c) atitudes enunciativas heterocentradas - aquelas que têm como referência o mundo e os discursos dos outros. "E é por via dessa atitude que o sujeito exibe sua competência axiológica, suas formações discursivas e ideológicas, seus posicionamentos sobre temas e aspectos da realidade social, política, cultural, econômica, religiosa, mundana etc." (EMEDIATO, 2015, p. 175).

É preciso observar que, não obstante haja a classificação das atitudes enunciativas em egocentradas, alocentradas e heterocentradas, as duas últimas também se voltam para a exibição de si, portanto, temos no Facebook como atitude enunciativa dominante a egocentrada (EMEDIATO, 2015), ou seja, todas as atitudes enunciativas envolvidas nessa rede social estão voltadas para a construção de si. Isso nos permite concluir que, quando alguém publica algo em sua linha do tempo, no Facebook, suas atitudes enunciativas permitem ao alocutário - aqueles que fazem parte da sua rede de amigos e o público em geral (dependendo da configuração de privacidade de sua conta,) - a construção do ethos do enunciador.

\subsection{Metodologia}

A fim de atender aos objetivos do presente estudo, procedemos com a análise de enunciações previamente selecionadas que circularam no Facebook. Para a seleção do corpus, levando em consideração a sua construção conforme a necessidade da pesquisa, fundamentamo-nos no que preceitua Baronas (2013), no sentido de que os corpora em Análise do Discurso não são dados a priori, de maneira que o que determinará como eles serão montados e frequentados será a questão de pesquisa. De acordo com o que enuncia Melo (2017),

[u]m dos principais problemas em análise do discurso é a constituição do corpus para pesquisa. Courtine (2014) afirma que a noção de corpus discursivo não deve ser considerada como um conjunto fechado de dados que emergiram de certa organização. Há, na verdade, um procedimento, o que implica que a construção do corpus seja concluída no final da pesquisa. O corpus passa, portanto, a ser composto por textos variados, de diversos gêneros e suportes em torno de um tema, de um conceito ou de um acontecimento. (no prelo 2017)

Ainda justificando a escolha do corpus no percurso da pesquisa, Marques (2011) afirma que a Análise do Discurso é um campo que não possui uma metodologia pronta no que se refere à pesquisa, ou seja, ao lançar mão dos elementos teóricos que fundamentarão a sua análise, o analista estará concomitantemente construindo seus procedimentos metodológicos, portanto, as pesquisas em Análise do Discurso, assevera Marques (2011) fundamentado em Orlandi, possuem sempre um caráter qualitativointerpretativista, não havendo, posto isso, análise quantitativa de dados. "Busca-se, no geral, realizar uma exaustividade vertical como dispositivo analítico (ORLANDI, 2009, p. 62) considerando os objetivos da pesquisa" (MARQUES, 2011, p. 62, grifo no original). 
O Facebook é uma rede social em que o discurso circula em quantidade incalculável, pois diariamente inúmeras postagens surgem, de maneira que esse espaço virtual se apresenta como um campo fértil para o estudo em tela. Formas de se mostrar nascem a cada publicação da linha de tempo, podendo ser aproveitadas por páginas institucionais que desejam se autopromover. Diante dessa conjuntura, Melo (no prelo 2017) afirma que "[t]al fato precisa ser considerado pelo analista, já que há uma fluência intensa dos dados através da interface, dentre os quais alguns podem ser considerados mais ou menos significativos para a mentalidade discursiva de acordo com o objetivo da pesquisa".

Seguindo essa linha de raciocínio e levando em consideração o objetivo deste estudo, ou seja, o exame da construção do ethos de páginas institucionais, selecionamos publicações realizadas nas timelines das páginas: Cemitério Jardim da Ressurreição e Parque das Acácias, criadas no Facebook, com o intuito de perceber como suas enunciações contribuem para a construção do ethos de cada uma delas. A seleção das páginas mencionadas se justifica pelo fato de serem perfis ativos que apresentam postagens que interessam a este estudo, e por, a priori, se mostrarem discursivamente de formas variadas, quando comparadas entre si, o que torna mais dinâmico o cotejo da construção de suas imagens.

Assim, a partir das publicações selecionadas, identificamos, mediante traços enunciativos - construções discursivas - do enunciador, sua corporalidade e seu caráter, além dos outros planos do ethos - o ethos pré-discursivo, o ethos discursivo ou mostrado e o ethos dito - a fim de compreender como esses enunciadores se mostram na rede social. Desse modo, tratando-se de uma pesquisa descritivo-interpretativa, de abordagem predominantemente qualitativa, nosso principal procedimento para a realização da análise será a identificação, a descrição e a interpretação dos traços característicos das enunciações selecionadas que contribuem para a construção do ethos do enunciador.

\section{Estudo do ethos das páginas Cemitério Jardim da Ressurreição e Parque das Acácias}

Nesta seção, dedicamo-nos à análise das páginas do Facebook de Cemitério Jardim da Ressurreição e Parque das Acácias, com o objetivo de compreender como suas enunciações contribuem para a construção do ethos de cada de seus enunciadores, partindo de publicações que foram realizadas nas timelines dessas páginas no período de agosto a novembro de 2016.

Conforme já apresentado na seção teórica, o enunciador em seu discurso constrói uma imagem de si, seja de forma intencional ou não, exercendo sobre o coenunciador determinada impressão, positiva ou negativa, a partir dos indícios textuais de que faz uso em sua enunciação. Em outras palavras, "o orador enuncia uma informação e, ao mesmo tempo, ele diz: eu sou isso, eu não sou aquilo" (BARTHES, 1975, apud AMOSSY, 2016, p. 10). E é justamente o que acontece com pessoas físicas ou jurídicas que criam perfis e páginas no Facebook, pois elas se mostram discursivamente de determinada forma para atender aos diversos fins a que se destinam, podendo ser de mera exibição à publicidade comercial. 
Antes de adentrarmos na análise das páginas selecionadas, pressuponhamos como ordinariamente seria a imagem de um cemitério, criada a partir de sua enunciação em uma propaganda publicitária. Ab initio, entendemos que palavras e imagens diretamente relacionadas com a morte, em regra, não se fariam presentes, tendo em vista que a morte é um tabu na cultura ocidental ${ }^{3}$; por outro lado, teríamos a assiduidade de elementos da natureza como: flores, pássaros, jardins, gramados e árvores, criando uma cenografia de sossego, de paz e de harmonia, características típicas de um lugar adequado para o descanso eterno.

Tais aspectos estão diretamente relacionados com a concepção de cemitério conferida por nossa cultura.

Mais do que uma instituição responsável por catalogar e asilar os restos mortais humanos, compreende um campo sagrado onde ocorrem manifestações sócio-culturais múltiplas; é um dos lugares onde o homem se relaciona com o transcendente, com o sobrenatural; é o local que nos questiona sobre qual o sentido da nossa existência. (MUNIZ, 2006, p. 161)

Diante disso, uma imagem ordinária de cemitério usada em propaganda publicitária pode ser a representada pela Figura 1, em que há a predominância de elementos da natureza em um dia ensolarado; os jazigos são discretos e adornados por placas de coloração clara e por flores, o que retira o ar sombrio de cemitérios; a enunciação "Onde os sentimentos são eternos" realça a ideia sentimental de apreço frente à de morte, enfim, o ethos do cemitério da propaganda endossa a imagem ordinária que podemos construir de um cemitério qualquer em propagandas publicitárias.

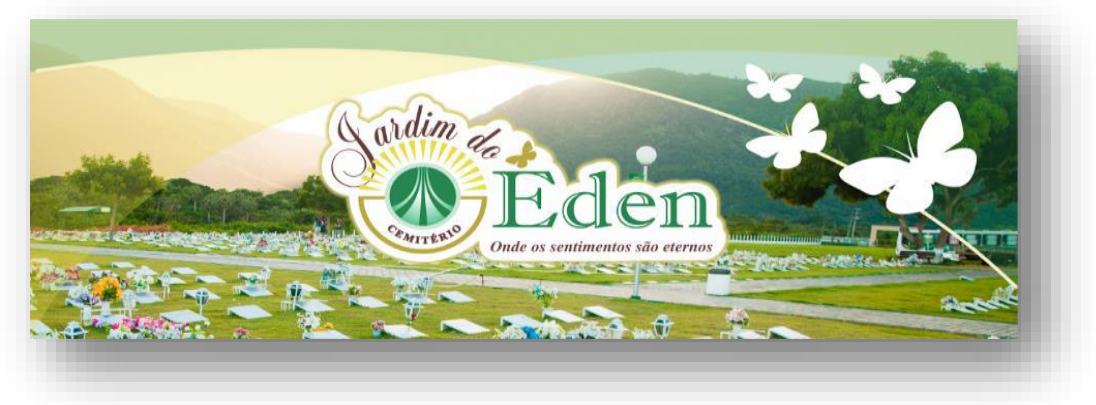

Figura 1. Exemplo de uma imagem ordinária de cemitérios.

Fonte: http://cemiteriojardimeden.com.br/category/acoes-nos-bairros/. Acesso em: 05 nov. 2016

Não obstante essa construção de uma imagem comum de cemitério, a página do Facebook do Cemitério Jardim da Ressurreição escapa desse ethos pré-discursivo ou prévio, aquele que, enquanto coenunciadores, construímos antes de termos acesso à sua enunciação. De acordo com Nascimento e Ferreira, "[...] ao anunciar um produto que alude a um tema indesejado como a morte, o discurso publicitário, por intermédio de suas

\footnotetext{
${ }^{3}$ Muniz (p. 163) entende que "[a] morte na História está envolta pelo silêncio, edificou-se um tabu sobre a morte e o morrer, sobretudo, sobre o cemitério. Quando citada, a morte é uma mera coadjuvante, nunca a protagonista. É negada ou mascarada, justificada pelo estigma do progresso" ( 2008, p. 163).
} 
empresas, pode escolher diversas formas de comunicação com seu público" (2016, p. 258). E é desse recurso que se utiliza a página ora estudada, ao construir um ethos que se afasta do sentimento de dor, assumindo características adiante apresentadas.

As páginas do Facebook, normalmente utilizadas por personalidades públicas e por instituições públicas ou privadas, com finalidades publicitárias, apresentam uma seção em que o seu dono pode descrever sua história. Nesse espaço, a página Cemitério Jardim da Ressurreição apresenta a sua missão nos seguintes termos: "Fornecer serviços de extrema qualidade em um ambiente acolhedor e sustentável, valorizando o respeito as (sic) diferentes crenças, perpetuando sempre a história das famílias com ética profissional e atendimento humanizado" 4 . Na página, o sujeito enunciador segue dizendo "[s]er referência como um dos melhores Cemitérios Parque do Nordeste".

Tais descrições representam o ethos dito do enunciador - informações fornecidas pelo enunciador sobre si que contribuirão para a construção do ethos não-discursivo que, por seu turno, será confrontado pelo destinatário com o ethos discursivo. Observamos, portanto, que as informações sobre si do enunciador ora estudado expressam um tom democrático e compromissado, implicando em um ethos de uma empresa preocupada com a sustentabilidade, a tolerância religiosa e o bem-estar de seus clientes, sendo, portanto, confiável e consciente.

No entanto, até aqui, a imagem criada, a partir do ethos dito do Cemitério Jardim da Ressurreição, não se distingue da ordinária que pressupomos para os cemitérios em geral, mas se confrontarmos o ethos dito com o ethos mostrado (ou discursivo), presente em suas enunciações, perceberemos quão afastada é a imagem desse enunciador da do Parque das Acácias, enunciador que, como veremos, se aproxima da imagem comum de cemitério.

A foto da capa do mês de novembro de 2016 do Cemitério Jardim da Ressurreição, (Enunciador 1), fazendo alusão ao mês de prevenção do câncer de próstata, traz as seguintes enunciações: "De quem você prefere levar uma cutucada?" e "Vamos combinar, a Dra. Morte é muito mais assustadora. Por isso, homarada com mais de 45 anos, cuide da sua saúde. Visite seu médico regularmente! O exame do toque não vai ferir sua masculinidade. \#NovembroAzul" (Fig. 2), sugerindo que o preconceito masculino, quanto ao exame de toque, pode levar à morte.

Observando a Figura 2, verificamos um ethos mostrado correspondente a um enunciador bem informado e atualizado, inclusive, pelo fato de sua adesão à campanha de conscientização sobre a importância do exame preventivo destinado ao diagnóstico precoce do câncer de próstata ter-se dado logo no dia $1^{\circ}$ de novembro. Os termos "cutucada", "homarada" e "Dra. Morte" ilustram bem a informalidade e o humor da enunciação, criando uma proximidade com o coenunciador. No tocante à materialidade não-verbal, na Figura 2, o sujeito posicionado no centro da imagem representa o homem que se vê diante da escolha que deve fazer entre a morte causada pelo câncer de próstata, simbolizada pelos braços e mãos de cor preta, e o exame de toque simbolizado pelas mãos com luvas brancas usadas pelos médicos para a realização de procedimentos, tais como o exame preventivo contra o câncer de próstata.

\footnotetext{
${ }^{4}$ Ethos dito do Enunciador 1. Disponível em https://www.facebook.com/cemijardimdaressurreicao/about/.
} Acesso em 05 nov. 2016. 
Ainda em relação à materialidade não-verbal, a expressão de apreensão desse sujeito representa o fato de que nenhuma das opções lhe agrada, sentimento próprio da maioria dos homens brasileiros que ainda encaram o exame de forma machista. Não obstante a tensão e a seriedade que envolvem o tema, a expressão do sujeito confere à enunciação exatamente o tom de humor intencionado pelos elementos verbais.

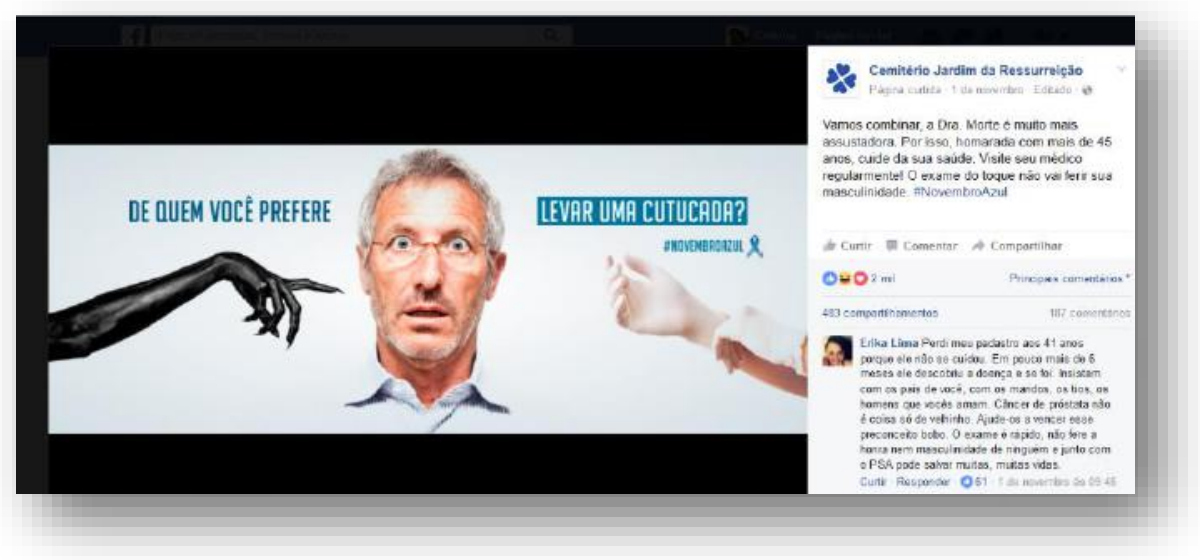

Figura 2. Foto da capa do mês de novembro/2016 do Enunciador 1. Fonte: https://www.facebook.com/cemijardimdaressurreicao/photos/a.585766508186632.1073741826.5857664348533 06/1112615005501777/?type=1\&theater. Acesso em: 05 nov. 2016.

Os enunciados apresentados (Figura 2) constroem uma cenografia de humor, em que morte e câncer são tratados de forma amenizada, sem, contudo, deixar de cumprir com o objetivo de divulgar a campanha, inserindo em seu discurso uma função social, a de chamar para a si responsabilidade de divulgar campanhas relacionadas à saúde e ao bem-estar dos cidadãos. A cenografia, assim, de acordo com Nascimento e Ferreira (2016), implica em um ethos, e afasta o quadro cênico, fazendo com que o coenunciador receba o discurso por outra cena.

O ethos bem-humorado e atualizado é endossado pelas publicações presentes na timeline da página. As enunciações a seguir (Figuras 3 e 4) exemplificam as formas das quais se utiliza o Enunciador 1 para mediar a cenografia que o distingue de um ethos melancólico, marcado pela dor e pela solidão, que nos remete um cemitério ordinário, a imagem culturalmente assentada acerca dos cemitérios e da morte de uma maneira em geral em nossa sociedade.

Observamos, desse modo, que a cenografia apresentada na página institucional do Enunciador 1 é validada por enunciações que tratam da morte - tabu na nossa cultura, como um tema qualquer, que paradoxalmente faz parte da vida.

Nas Figuras 3 e 4, o Enunciador 1 incorpora-se às peculiaridades das materialidades discursivas no Facebook, por meio de publicação de meme (Figura 4) e de resultado de teste de perfil (Figura 3), tão presentes nessa rede social. 


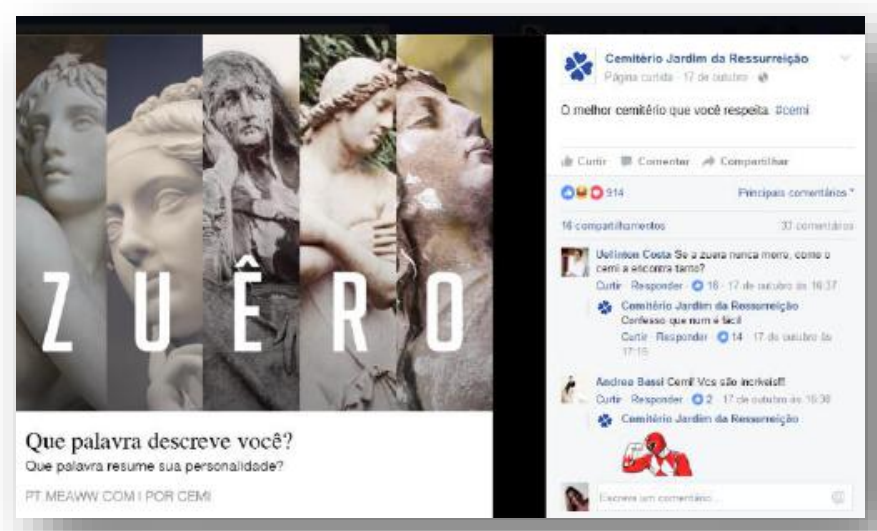

Figura 3. Publicação na timeline do Enunciador 1. Fonte:

https://www.facebook.com/cemijardimdaressurreicao/photos/a.586323488130934.1073741828.5857664348533 06/1097117293718215/?type=3\&theater. Acesso em: 05 nov. 2016.
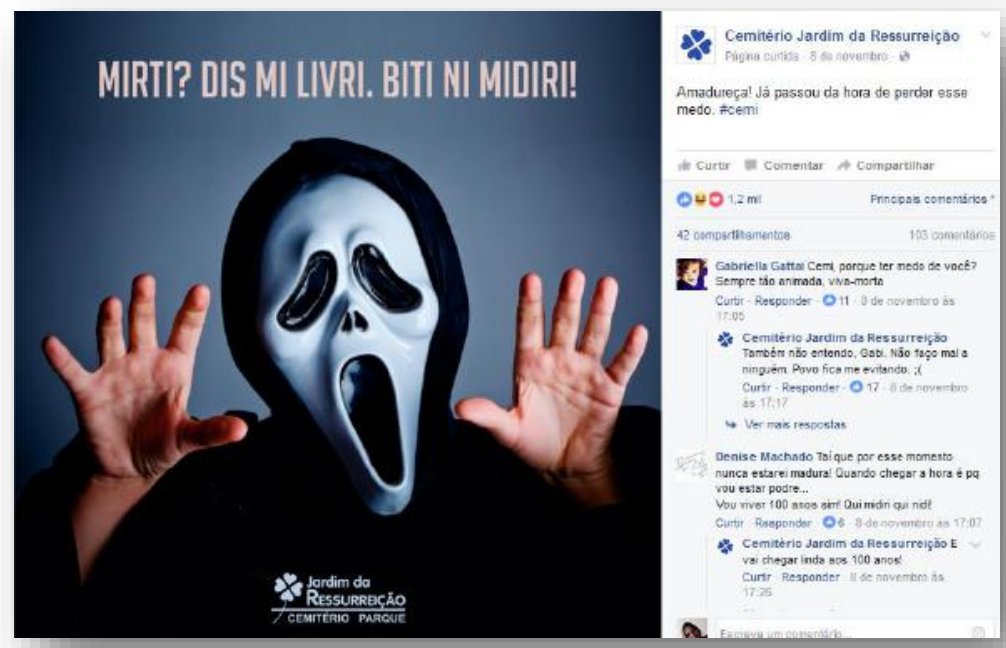

Figura 4. Publicação na timeline do Enunciador 1. Fonte:

https://www.facebook.com/cemijardimdaressurreicao/photos/a.586323488130934.1073741828.5857664348533 06/1121543011275643/?type=3\&theater. Acesso em: 11 nov. 2016.

Esse comportamento do Enunciador 1, demonstrado para seus coenunciadores mediante suas publicações, afiança o ethos dotado - além do bom-humor já tão explicitado, pois trata da morte de forma mais natural - de uma atitude conformista, positiva e, consequentemente, sem o tom de tristeza e dissabor como somos culturalmente condicionados a adotar diante do tema morte.

Importante notar que, embora, à primeira vista, possa parecer contraditório o fato de o Enunciador 1 - bem como o Enunciador 2, como veremos adiante - valorizar a vida, contrariando a ideia de publicidade de cemitérios, a adesão a campanhas como a ora tratada integra o discurso da reponsabilidade social no âmbito da publicidade. Disso 
decorre a existência de ethé como o do Enunciador 1, bem-humorado, mas também dotado de uma imagem preocupada com o bem-estar e com a saúde de possíveis clientes.

Ainda no sentido de valorização da vida, na Figura 5, ao fazer alusão ao dia de finados, o Enunciador 1 enfatiza o dia como o de homenagem a quem está vivo na memória, fazendo menção aos que morreram, sem, contudo, utilizar o vocábulo morte. Nota-se que a porção da enunciação "hoje é dia de homenagear quem está vivo" está em caixa alta, com tamanho da fonte maior e cor da fonte mais viva, enquanto que a porção da enunciação, que nos remeteria diretamente à data de comemoração dos mortos ("na lembrança" e "2/11 - dia de finados"), se aparecesse com a mesma configuração da parte enunciativa inicial, está com tamanho menor e cores apagadas.

Assim, em uma passada de olhos não muito atenta sobre a Figura 5, teríamos a impressão de que o enunciado termina no vocábulo "vivo", o que configura o modus operandi da cenografia criada por esse enunciador que deixa a ideia negativa de morte para um segundo plano em suas enunciações.

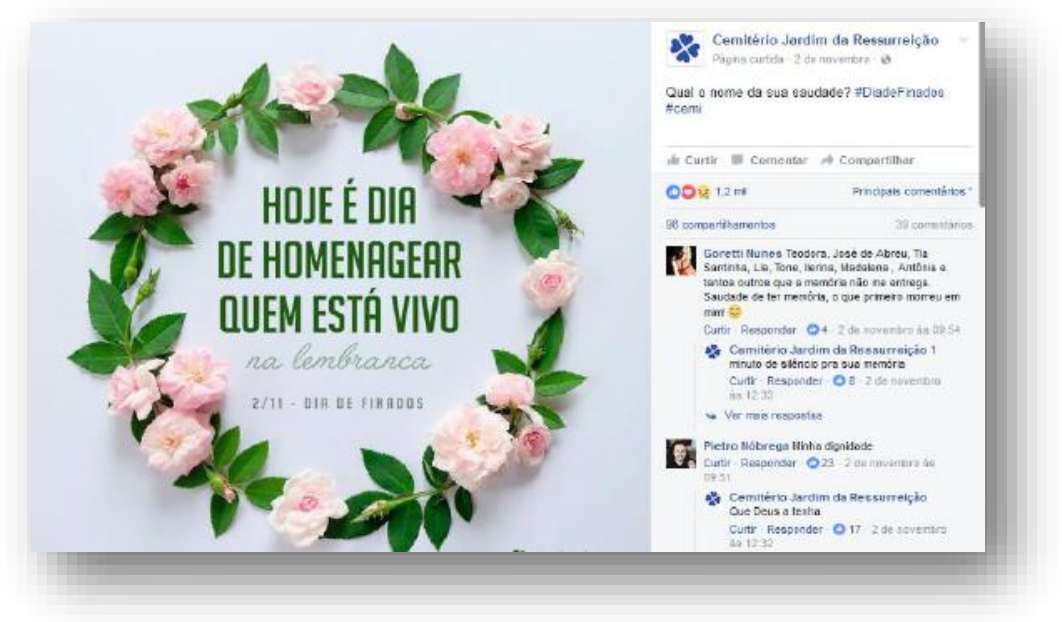

Figura 5. Publicação na timeline do Enunciador 1. Fonte:

https://www.facebook.com/cemijardimdaressurreicao/photos/a.586323488130934.1073741828.5857664348533 06/1113155412114403/?type=3\&theater. Acesso em: 05 nov. 2016.

Notando o número de curtidas que ocorreram nessa publicação (1,2 mil até 05 de novembro de 2016), concluímos que a adesão dos coenunciadores foi mais significativa, se compararmos a ocorrida com a publicação realizada com o mesmo fim - homenagem aos finados - na página Parque das Acácias, que teve apenas 58, embora o vídeo tenha sido visualizado 4,1 mil vezes (Figura 6). Acerca das visualizações, é necessário que nos atentemos ao seguinte: somente vídeos apresentam tal contagem. Não obstante esse cômputo, não deve ser considerado como adesão, já que os coenunciadores não se manifestaram por meio dos atos de linguagem utilizados pelos sujeitos que participam do dialogismo interacional no Facebook: curtir, compartilhar e comentar. 


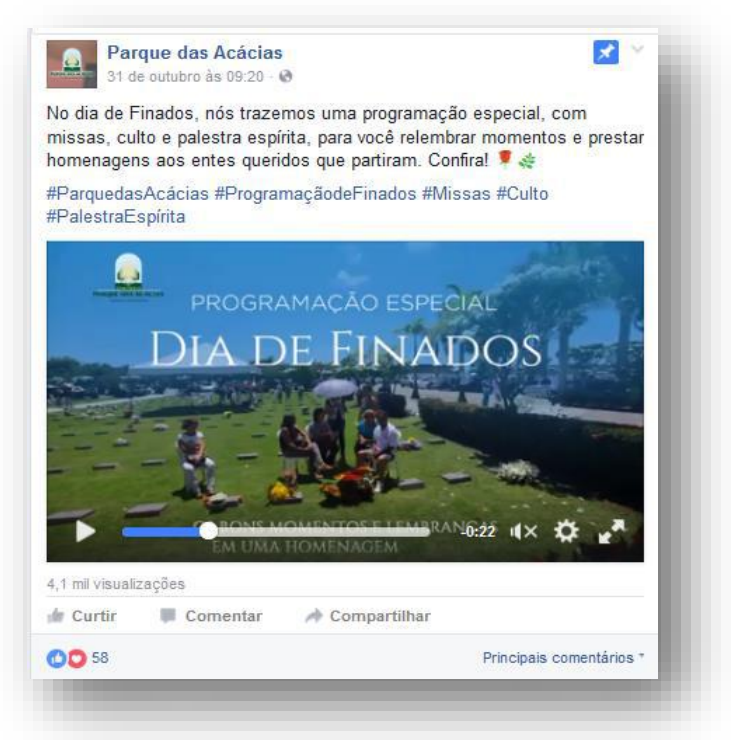

Figura 6. Publicação na timeline do Enunciador 2. Fonte: https://www.facebook.com/parquedasacaciasoficial/videos/vb.298585280330405/563206837201580/?type=2\&t heater. Acesso em 05 nov. 2016

Ambas as enunciações (Figuras 5 e 6) tratam do mesmo tópico, remetendo o coenunciador ao dia de finados, mas apresentam adesões diferentes conforme dito, mas por que isso ocorre? De acordo com Maingueneau,

[o] universo de sentido que o discurso libera impõe-se tanto pelo ethos quanto pela "doutrina"; as "ideias" apresentam-se por uma maneira de dizer que remete a uma maneira de ser, à participação imaginária de um vivido. O texto não é para ser contemplado, ele é enunciação voltada para um coenunciador que é necessário mobilizar para fazê-lo aderir "fisicamente" a um certo universo de sentido. O poder de persuasão de um discurso decorre em boa medida do fato de que leva o leitor a identificar-se com a movimentação de um corpo investido de valores historicamente especificados. (MAINGUENEAU, 2016, p. 73, grifos no original)

Assim, o Enunciador 1 utiliza uma série de recursos para promover um ethos mais clean, de forma desarticulada da ideia de morte em uma acepção mais fúnebre e melancólica. Além de enunciações relacionadas a ações praticadas no Facebook pelos usuários dessa rede social, como compartilhar memes e participar dos testes que são disponibilizados para os usuários, o enunciador apresenta opções de utilização do espaço físico do cemitério para outras atividades totalmente separadas do seu fim imediato. De acordo com a Imagem 7, o enunciador, ao mesmo tempo em que convida à utilização do espaço do cemitério para atividade física, promove-se, divulgando sua área.

Na Figura 7, a publicação é composta de uma foto que mostra, em primeiro plano, um aplicativo de smartphone utilizado por esportistas, com vistas a registrar o tempo e o percurso de uma corrida. No caso, o percurso que aparece na tela do celular tem a forma de um hexágono semelhante a um esquife, índice que confere à enunciação o característico tom de humor do Enunciador 1. Em segundo plano, a foto mostra uma área 
de túmulos do cemitério, mas sem foco, explicitando a intenção do enunciador de mostrar aos seus coenunciadores que se trata de um cemitério, mas que, apesar disso, seu espaço físico é apropriado para práticas esportivas como a corrida. Ainda endossando o tom de humor, a foto apresenta a enunciação "R.I.P. Sedentarismo" e "Aqui é cemitério, mas também é parque. E como parque, é ideal para uma corridinha. São 11 hectares para você pagar de mus@ fitness. Vem! \#cemihttps://goo.gl/maps/WvGtX8bPgks", desconstruindo a imagem de um espaço macabro e insalubre.

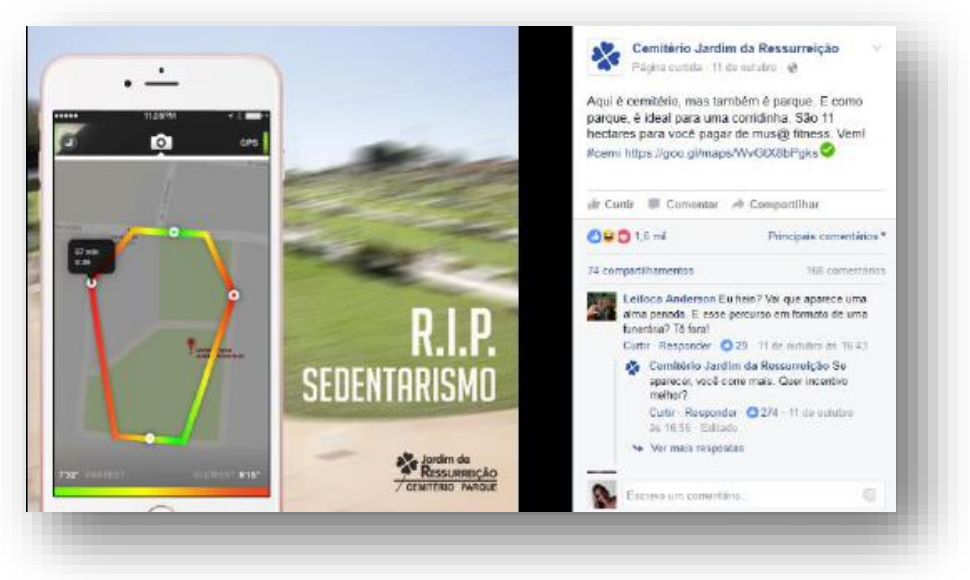

Figura 7. Publicação na timeline do Enunciador 1. Fonte:

https://www.facebook.com/cemijardimdaressurreicao/photos/a.586323488130934.1073741828.5857664348533 06/1091357837627494/?type=3\&theater. Acesso em 05 nov. 2016.

Importante observar que, muito embora, o coenunciador se depare com uma cenografia incomum daquela dos cemitérios em geral, e o ethos discursivo apresente enunciações engraçadas e seja contumaz em brincadeiras irônicas acerca do tema morte, o ethos dito - as informações que o Enunciador 1 traz a respeito si na seção "sobre" da sua página - não é contrariado pelo ethos discursivo. Assim, apesar de a dimensão psicológica (o caráter) do enunciador seja característica de um ethos divertido, esse fato não anula o seu caráter de empresa compromissada e séria, traços que compõem o ethos dito, informados na seção mencionada.

Seguindo, agora, para o estudo da página institucional do Parque das Acácias (Enunciador 2), veremos que, ao contrário do ethos construído pelas enunciações do Enunciador 1, suas enunciações colaborarão para a construção de um ethos comum aos cemitérios em geral. O ethos dito criado a partir das enunciações contidas na seção "sobre" da página do Facebook do Enunciador 2 colaboram para a construção de uma dimensão física (corporalidade) correspondente a de uma empresa que oferece um ambiente agradável e dotado de uma infraestrutura completa para bem atender seus clientes, e de uma dimensão psicológica (caráter) de uma empresa sólida, confiável e também preocupada com o meio ambiente devido às informações que traz na referida seção ${ }^{5}$.

\footnotetext{
${ }^{5}$ Ethos dito do Enunciador 2, disponível em https://www.facebook.com/parquedasacaciasoficial/about/. Acesso em 11 nov. 2016.
} 
Mediante seu ethos dito, o Enunciador 2 não apresenta qualquer cunho religioso em sua enunciação, nem menciona, como fez o Enunciador 1, a valorização das diferentes crenças $^{6}$ (Figura 8), no entanto, nas enunciações da timeline, que colaboram na construção do ethos discursivo, observamos publicações de vídeos referentes a celebrações religiosas de cunho cristão.

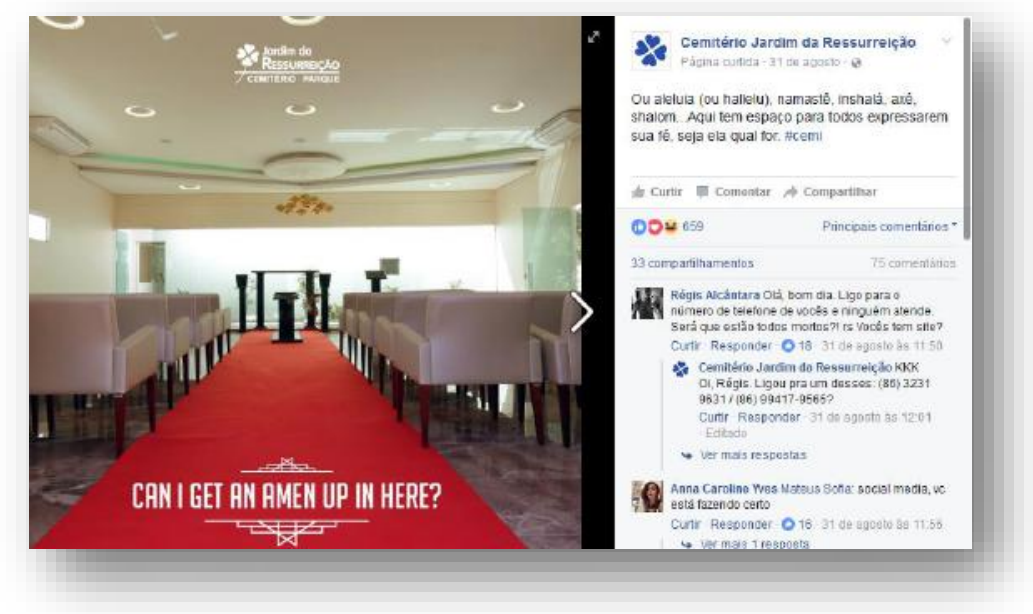

Figura 8. Publicação na timeline do Enunciador 1. Fonte:

https://www.facebook.com/cemijardimdaressurreicao/photos/a.586323488130934.1073741828.5857664348533 06/1056713327758612/?type=3\&theater. Acesso em: 11 nov. 2016.

Também preocupado em construir uma imagem de empresa engajada nas campanhas preventivas contra o câncer de próstata, o Enunciador 2 publicou em sua timeline, como foto da capa, a Figura 9, com tom de seriedade próprio do tema.

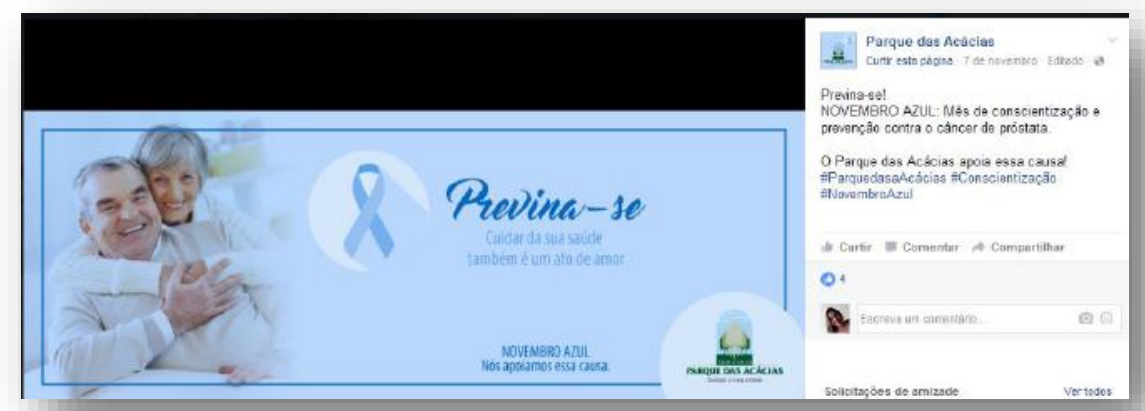

Figura 9. Foto da capa do mês de novembro/2016 do Enunciador 2. Fonte: https://www.facebook.com/parquedasacaciasoficial/photos/a.298585376997062.1073741827.29858528033040 5/566780423510888/?type=1\&theater. Acesso em: 11 nov. 2016.

\footnotetext{
6“'Ou aleluia (ou hallelu), namastê, inshalá, axé, shalom.... Aqui tem espaço para todos expressarem sua fé, seja ela qual for. \#cemi” (Figura 8).
} 
$\mathrm{Na}$ enunciação apresentada na Figura 9, é evocado o discurso de campanha publicitária, com uma cenografia em que o coenunciador se esbarra com o compromisso, com a responsabilidade de cuidar de si como "um ato de amor" (Figura 9), que reporta o coenunciador à sua família, no sentido de dizer que "se você ama a sua família, você cuida de si", sem o tom misantropo de que se utiliza na foto da capa que adere à campanha contra o câncer de mama ${ }^{7}$. Porém, tanto em uma quanto na outra foto da capa, o ethos dito é confirmado pelo ethos discursivo, ou seja, a seriedade permeia as cenas de enunciação a todo o momento, até mesmo, nas publicações da timeline, como passamos a analisar.

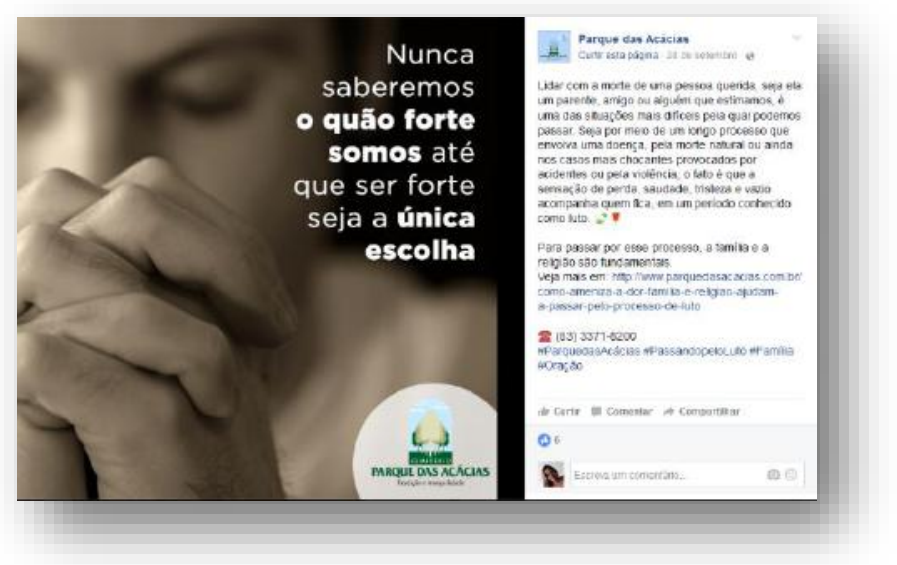

Figura 10. Publicação na timeline do Enunciador 1. Fonte: https://www.facebook.com/parquedasacaciasoficial/photos/a.299350750253858.1073741828.29858528033040 5/548280735360857/?type=3\&theater. Acesso em: 05 nov. 2016.

Ao enunciar "Nunca saberemos o quão forte somos até que ser forte seja a única escolha" de forma conjugada com a foto de uma pessoa com gesto que sinaliza estar em oração (Figura 10), o Enunciador 2 refere-se ao luto, sem utilizar os termos morte, doença, tristeza, perda, reportando o coenunciador a um discurso de autoajuda, ressaltando a ideia de pujança que se deve ter, mesmo nas piores circunstâncias.

O discurso de autoajuda também é utilizado na enunciação que acompanha a Figura 10 na publicação, sendo que esta enunciação adota os vocábulos que foram ocultados na enunciação anterior (a conjugada com a imagem em que a pessoa se encontra com as mãos em sinal de prece), enunciando outros que especificam as formas de morte. Nesse tocante, é importante notar que esse enunciador, apesar de não ocultar o tema, interpela o luto com um tom melancólico.

Considerando que as páginas institucionais analisadas são pessoas jurídicas de direito privado (art. 44, Código Civil) com fins lucrativos, já que praticam o comércio, é previsível que seu objetivo publicitário seja a venda de seu produto. Assim, no tocante ao enfoque de mercado, o Enunciador 2, apesar da presença do discurso de autoajuda e do

7 Foto da capa do Enunciador 2 aderindo à campanha contra o câncer de mama, disponível em https://www.facebook.com/parquedasacaciasoficial/photos/a.298585376997062.1073741827.2985852803 30405/559801880875409/?type=1\&theater. Acesso em 11 nov. 2016. 
discurso que valoriza a importância da saúde, da preservação da vida, da família, dos amigos $^{8}$, por exemplo, explicita o seu intuito mercadológico com enunciações em que se apresenta explicitamente como produto ${ }^{9}$.

O Enunciador 1, por sua vez, em suas enunciações, trata estrategicamente do seu produto, ao abordar de maneira irônica e divertida a morte, sem declarar diretamente o "eu quero vender" (Figura 11).

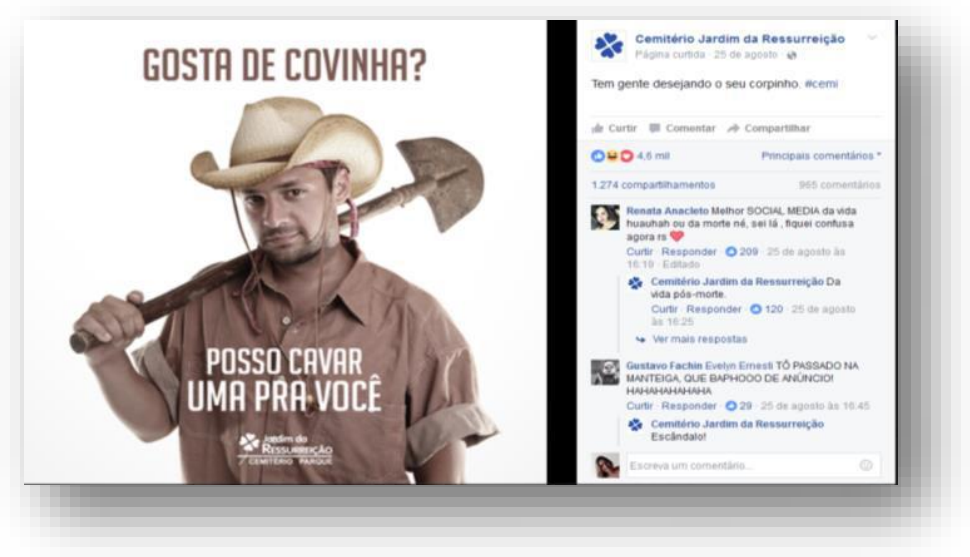

Figura 11. Publicação na timeline do Enunciador 1. Fonte:

https://www.facebook.com/cemijardimdaressurreicao/photos/a.586323488130934.1073741828.5857664348533 06/1051972371566041/?type=3\&theater. Acesso em: 12 nov. 2016.

Como se percebe, o Enunciador 1, ao apresentar o seu produto, desenvolve uma cenografia distinta da do Enunciador 2 e se utiliza de uma enunciação fora da cena genérica (propaganda publicitária de venda), apropriando-se de uma forma de comunicação com o coenunciador sobre um tema indesejado a qual desloca esse produto da condição de objeto de consumo, passando a promovê-lo como protagonista da cena enunciativa.

\section{Comentários conclusivos}

A partir da análise das páginas Cemitério Jardim da Ressurreição (Enunciador 1) e Parque das Acácias (Enunciador 2), foi possível perceber como o discurso publicitário pode apresentar cenografia e ethos distintos, e como esses elementos discursivos provocam reações diferentes diante de seus coenunciadores no âmbito das redes sociais.

8. Exemplo de enunciação do Enunciador 2 não relacionada diretamente à morte ou ao luto: https://www.facebook.com/parquedasacaciasoficial/photos/a.299350750253858.1073741828.2985852803 30405/555021248020139/?type=3\&theater.

9. Exemplo de enunciação em que o Enunciador 2 se apresenta como produto de mercado de forma explícita: https://www.facebook.com/parquedasacaciasoficial/photos/a.299350750253858.1073741828.2985852803 30405/534661363389461/?type=3\&theater. 
O Enunciador 1, partindo de uma cenografia própria da de um usuário comum de rede social que participa e publica resultado de testes, que coopera com campanhas em voga, que acompanha as tendências das redes sociais publicando memes, promove seu produto indiretamente e constrói um ethos cujo fiador é um indivíduo divertido, irônico e trata um assunto como a morte de uma forma bem-humorada, sem, contudo, ser desrespeitoso. O Enunciador 2, por outro lado, usa uma cenografia própria da propaganda publicitária. Muito embora trate de assuntos diversos que colaboram para a construção de um fiador cujo ethos é sério, sólido e engajado, oferece sua mercadoria de forma explícita, mas respeitosa também. Como se vê, são formas distintas de se mostrar, que, consequentemente, fazem surtir efeitos diferentes entre os seus coenunciadores, pelo menos no Facebook, espaço em que se limita esta pesquisa.

Observando a seção "curtidas" das páginas de ambos os enunciadores, foi possível perceber a diferença dos efeitos gerados nos coenunciadores. Em 12 de novembro de 2016, o total de curtidas na página do Enunciador 1 foi 45.982 , enquanto que na do Enunciador 2 foi 2.442. Se ignorarmos tais informações e partimos para a comparação das publicações individualizadamente, durante o período analisado (de agosto a novembro de 2016), também verificaremos que as adesões dos coenunciadores às enunciações do Enunciador 1 são em maior quantidade que as adesões às enunciações do Enunciador $2^{10}$.

Diante de tais dados, podemos depreender que o Enunciador 1 consegue obter maior adesão dos internautas com conta no Facebook que o Enunciador 2. Levando em consideração que o produto comercializado pelos enunciadores é o mesmo, bem como o fato de que ambos se utilizam de idêntico suporte (a interface do Facebook), são os elementos discursivos utilizados nas publicações que constituem o diferencial entre os enunciadores.

\section{Referências}

AMOSSY, R. Da noção retórica de ethos à análise do discurso. Em: AMOSSY, R. (Org.). Imagens de si no discurso: a construção do ethos. São Paulo: 2016. pp. 9-28.

BARONAS, R.L. Da panaforização à metaforização: o caso de uma pequena frase sem eira nem beira textual. Revista da ABRALIN, Universidade Federal do Paraná, Curitiba, v. $12, \quad$ n. 2, 219-248, 2013. Disponível em http://revistas.ufpr.br/abralin/article/view/38249. Acesso em 10 out. 2016.

EMEDIATO, W. Discurso e web: as múltiplas faces do Facebook. Revista da ABRALIN, Universidade Federal do Paraná, Curitiba, v. 14, n. 2, 171-192, 2015. Disponível em http://ojs.c3sl.ufpr.br/ojs/index.php/abralin/article/view/42561. Acesso em 26 out. 2015.

\footnotetext{
${ }^{10}$ Por exemplo, nos dados das fotos das capas dos enunciadores referentes à campanha Novembro Azul de 2016, temos: 2 mil curtidas para o Enunciador 1, em 05 de novembro de 2016; e 4 curtidas para o Enunciador 2, em 11 de novembro de 2016.
} 
MAINGUENEAU, D. Ethos, cenografia, incorporação. Em: AMOSSY, R. (Org.). Imagens de si no discurso: a construção do ethos. São Paulo: 2016. pp. 69-92.

Ethos e apresentação de si nos sites de relacionamento. Em: Doze conceitos em análise do discurso. São Paulo: Parábola Editorial, 2010. pp. 79-98.

A propósito do ethos. Ethos discursivo. São Paulo, Contexto, 11-29, 2008. Disponível em <http://www.martinsfontespaulista.com.br/anexos/produtos/capitulos/509327.pdf>. Acesso em 10 out. 2016.

Análise de textos de comunicação. São Paulo: Cortez, 2004.

MARQUES, W. Metodologia de pesquisa em análise do discurso face aos novos suportes midiáticos. Domínios de Lingu@Gem, Universidade Federal de Uberlândia, Uberlândia, v. $5, \quad$ n. $\quad 1, \quad 58-73, \quad 2011 . \quad$ Disponível em http://www.seer.ufu.br/index.php/dominiosdelinguagem/article/view/12277/8054.

Acesso em 25 out. 2016.

MELO, L.B. Avaliando gêneros digitais e contexto interacional em atividades pedagógicas para aprendizagem móvel no Facebook. V Simpósio Hipertexto e Tecnologias na Educação, I Colóquio Internacional de Educação com Tecnologias, Pipa Comunicação, 1-15, Recife, 2013. [Anais]. Disponível em http://www.nehte.com.br/simposio/anais/Anais-Hipertexto-

2013/Avaliando $\% 20 \mathrm{~g} \% \mathrm{C} 3 \%$ AAneros $\% 20$ digitais $\% 20 \mathrm{e} \% 20$ contexto $\% 20$ interacional $\%$ 20em\%20atividades \%20pedag\%C3\%B3gicas\%20para\%20aprendizagem $\% 20 \mathrm{~m} \% \mathrm{C} 3 \%$ B3vel\%20no\%20Facebook.pdf. Acesso em 18 fev. 2016.

. A imagem de candidato à presidência no Facebook: ethos, cenografia e uso de pequenas frases. (no prelo, 2017)

MUNIZ, P.H. O estudo da morte e suas representações socioculturais, simbólicas e espaciais. Varia Scientia, Universidade Estadual do Oeste do Paraná, Cascavel, v. 6, n. 12, 159-169, 2006. Disponível em https://www.mysciencework.com/publication/show/67593395f2f53b93d0ef81f2d611d4 10. Acesso em: 14 nov. 2016.

NASCIMENTO, J.V.; FERREIRA, A. Mimotopia e cenografia no discurso publicitário de empresas de seguro de vida e de assistência funerária. Calidoscópio, Universidade do Vale do Rio dos Sinos, São Leopoldo, v. 14, n. 2, 257-264, 2016. Disponível em http://revistas.unisinos.br/index.php/calidoscopio/article/view/cld.2016.142.08. Acesso em 09 nov. 2016.

REIS, C. As postagens no Facebook: uma análise dialógica da página de humor "Dilma Bolada". Dissertação. Mestrado em Linguística e Língua Portuguesa, Faculdade de Ciências e Letras, Universidade Estadual Paulista "Júlio de Mesquita filho", Araraquara, São Paulo, 2015. 
Artigo recebido em: junho de 2017.

Aprovado e revisado em: outubro de 2017.

Publicado em: novembro de 2017.

\section{Para citar este texto:}

DUARTE, Cristina Rothier; SILVA, Francisco Vieira da. Do ethos sóbrio ao divertido em enunciações sobre a morte: uma análise de páginas institucionais no Facebook. Entremeios [Revista de Estudos do Discurso, on-line, www.entremeios.inf.br], Seção Temática [Linguagem e Tecnologia], Programa de Pós-Graduação em Ciências da Linguagem (PPGCL), Universidade do Vale do Sapucaí (UNIVÁS), Pouso Alegre (MG), vol. 15, p. 225-245, jul. - dez. 2017.

DOI: http://dx.doi.org/10.20337/ISSN2179-3514revistaENTREMEIOSvol15pagina225a245 